Andreas Heck, Zoltán Szegedi, Marcus Störkel

\title{
4.5 ROLE OF REGIONAL CLUSTER DEVELOPMENT CASE STUDY: SUPPORTING VIRTUAL ENTERPRISES (VE)
}

\begin{abstract}
Summary: Clusters in general are a particularly important way through which location-based complementarities are realized.

This paper shows one example of regional cluster composition in the economic performance of industries, clusters and regions in the field of the Telecommunication sector in Germany. It examines the role of regional clusters in regional entrepreneurship. We focus on the distinct influences of convergence and agglomeration on growth in the number of start-up firms as well as in employment in these new firms in a given region of a special industrial sector.

The first step in the lifecycle of a virtual enterprise is the identification of potential companies or company departments which have a common business goal. In order to approach the seed identification problem of virtual companies, three basic sub-problems have to be solved. Firstly, relevant company data and information have to be acquired. Secondly, the information has to be analysed in order to find common aspects and business goals. Thirdly, selection criteria have to be defined in order to decide whether a company might be part of the virtual enterprise or not.

The paper at hand presents an approach to semi-automate the seed identification of the Mobile Communication Cluster. Its use inside a company gives rise to the discovery of new business opportunities through automated business segment analysis.
\end{abstract}

Keywords: regional cluster, telecommunication, virtual enterprises

\section{INTRODUCTION}

This paper shows the Mobile Communication Cluster (MCC) cluster and the Deutsche Telekom technology programs which receive funding by the federal government and the foundation of Deutsche Telekom AG.

MCC aimed at the advancement of the business competition of a weakly developed region through the generation of a virtual enterprise. MCC was initiated by the „wir4Region“ Business Development Network for the cities of Moers, Kamp Lintfort, Neukirchen Vluyn und Rheinberg. It was supported by the European Commission, the Ministry of Commerce and Work North Rhine-Westphalia (NRW), the Initiative for Innovative Communication NRW and the Deutsche Telekom AG. Hence, the MCC is a perfect example of a cluster in the sense of (Porter, 1998) and it fits the requested innovation capabilities defined in (Roettmer and Katzy, 2006). The objective of MCC was to actively support the process of cluster creation by

a) identifying adequate companies by profile screening

b) a goal directed merger of cluster companies in order to define a new competence profile

c) representing the new competence focal point to the conjoint market

d) developing a virtual umbrella organization

e) setting up a real organization responsible for

i) the acquisition of high potential customers

ii) the definition of common rules within the cluster and

iii) the appointment of competent managers. 
Expectation of Cluster projects in general:

Most of cluster projects show positive results in respect to the economic output of these programs. Several critical factors could limit the quantitative evaluation of the impacts of these programs. These are due to the emergent character of the targeted developments, the complex impact patterns and the considerable time-lags of state financing.

Proposed advantages: Companies participating in a strong cluster register higher employment growth and patenting due to forming to virtual enterprises and strong co operations. Industry and cluster level growth also increases with the strength of related clusters in the region.

Public financing of cluster activities, research institutions and other organizations is based on the observation that networking plays an increasing role in technological progress. Due to this fact the installation of a solid working base due to the cooperation with Deutsche Telekom AG (the largest telecommunications provider in Germany) is important.

\section{LITERATURE REVIEW}

The first step of the MCCs objective, namely "identifying adequate companies by profile screening" makes highest demands on the project. Actually (Kanet, Faisst, and Mertins, 1999) define a key function to this objective as follows:

"During the formation phase, a key activity is to identify suitable partners as specified by the partnership architecture. Finding potential partners can be facilitated either through an internal partner database of the broker, or through internet search of enterprise presentations. An internal partner database, i.e., a network of entities (potential partners) including an inventory of partner capabilities and capacities, could be constructed. Upon definition of a particular mission, the network could be searched for specific recommendations for possible partners. An internet search of enterprise presentations could be facilitated by so-called ,intelligent software agents“ for organizing and systematically filtering ,hits"."

Kanet et al. (1999) either assume that there is already a partnership architecture, i.e. the subsequent steps of MCCs objectives would be solved, or they suggest the installation of a broker who would be able to select the companies for the cluster from a given database which needs to be filled with all necessary information. The broker might be assisted by an intelligent agent who would be able to analyse homepages of companies in order to suggest potential cluster partners. If there is no pre-filled database, no partnership architecture, no idea for the intelligent agents what to search for, but there is a set of companies defined only by their regional affiliation and the political will to support the innovative power of that region, then we are faced with a problem which precedes the cluster formation phase, namely the Seed Identification Problem.

In the following this specific question will be addressed. After defining the Seed Identification Problem, it will be shown how intelligent document analysis techniques could be used as the (new) first step of the cluster creation process. The essential ingredients of the method are

1. the use of standard company document material,

2. the application of an intelligent document analysis system, and

3. the integration of semantic technologies.

It will be also described how the technology can be used for the development of a dedicated R\&D-cluster. Eventually its use inside a company is discussed with the aim of discovering new business opportunities through automated business segment analysis.

The development of regional R\&D clusters based on innovative technical instruments and requires cultural settings for the involved companies such as joined communication, 
knowledge sharing and the usage of web technologies for collaborating. Virtual working is highly innovative and flexible.

Web-based communities are a real example for self organization of people. Open innovation is a change in attitude.

"Being open to the knowledge of others", "common knowledge to create" and "knowledge to share with others" are the central principles. (Chesbrough, H. 2003).

Open Innovation is about radical upheaval in innovation management. The approach is for the active strategy of developing the collective knowledge base, creativity and innovation opportunities. The Internet is a central driver and success factor for the development of distributed, open and interactive innovation systems. (Michael Bartl, 2010)

"Taking the efficiency of $R \& D$ expenditure as a measure of the quality of a regional innovation system (Fritsch, 2002), there is significant variation showing some correspondence to a center-periphery hypothesis that suggests better conditions for innovation activity in the center as compared to more remote areas or regions characterized by a relatively low degree of agglomeration (the periphery). An analysis of the German regions in the sample has found that the interregional differences in the efficiency of their respective innovation activity can be explained to a considerable degree by differences in the amount of regional knowledge spillovers (Fritsch and Franke, 2000). This result supports the hypothesis that the interaction of the elements of a regional innovation system is of crucial importance for its performance."

"In order to improve the R\&D efficiency of local firms, it is important to construct a widerange collaborative network within and beyond the clusters, although most clusters focus on the network at the narrowly defined local level. These characteristics may be important factors for the effective organization of cluster policies." (Nishimura, Okamuro; 2009)

\section{THE SEED IDENTIFICATION PROBLEM}

Of course, in most VE life cycle models (cf. Becker et al., 2005) there is a "pre-phase" preceding the formation phase. (Kanet, Faisst, and Mertins, 1999) introduced the "identification phase" as the first step of their life cycle model on the following.

"During the first phase of the development of a VE, the „Identification“" phase, the broker is the driving force for searching for and recognizing market opportunities, planning and drafting the value chain that will eventually comprise the VE, and estimating costs and revenues."

And later

"During the identification phase of a VE, the broker can make good use of tools such as online databases (user interfaces needed), newsgroups and the WWW within the internet."

Though their definition of the identification phase does not answer the question where the above mentioned support and information for the formation phase comes from. We identified this spesific problem within the identification phase as the Seed Identification Problem (SEP):

Given a set of companies, select a perfect subset (non-empty, more than one) such that the selected companies are well suited to form a virtual enterprise. According to (Porter, 1998) the companies either follow identical business goals or their competencies fit to define a common new business goal.

In order to solve the SIP, a profile screening process for companies has to be defined together with a set of success criteria. The screening process requires a catalogue of company attributes and a soft matching function which map the attributes to the success criteria. In the following this approach will be presented in detail on the basis of a cluster creation process. 


\section{THE CLUSTER CREATION PROCESS}

The cluster creation process is basically supported by intelligent searching, contextual comparison, and matching of unstructured data. Only two steps of the complete so called "four step process" have to be performed by the process owner. The acquisition of relevant company information and the analysis of the data is done by the conducted knowledge framework (Fitza, 2004) technology which can be based on an integrated document capturing, analysis, and clustering approach.

The integrated document capturing starts with the associative search engine that works similar to standard search engines (like google). The so called Nextbot Knowledge Framework (NKF) combines intelligent functionalities like fuzzy search, relevance assessment, resemblance search, contextual weighting and non-standard assortments of sets of documents. Core of the associative search is the extraction of summaries from documents. These summaries describe the essential content signs of every document. The associative search works linguistic-independently. Documents of different languages can be administered in the same index.

The first step in creating a virtual R\&D Cluster is the aggregation to a summary document cluster that includes the contextual assortments of all documents and shows the whole cluster size. The organizational and technical framework supports an efficient hierarchical clustering process and enhances the knowledge development inside the cluster based on the defined legislation corpus. The exact definition of knowledge rules is the key success factor inside clustering processes (Becker et al, 2005).

Figure 1 visualises the four main phases together with their basic activities:

Figure 1 The four main phases together with their basic activities

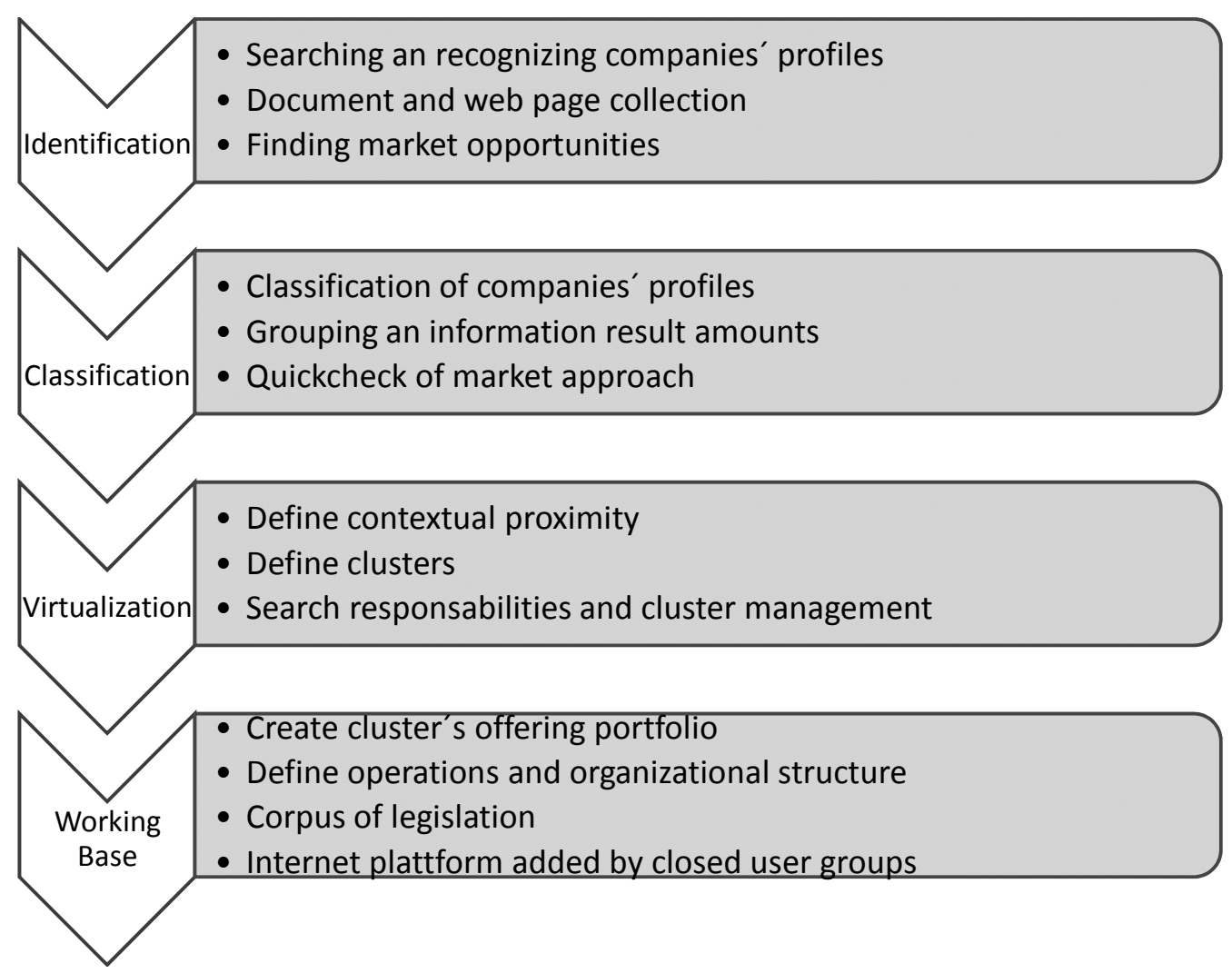

Source: Deutsche Telekom, department of new business development: working paper, IuK Business Development - case study, pp. 12-18, Bonn, 2007 
Summarizing the process which starts with a collection of documents and ends with a suggestion of potential company clusters the MCC core processing is devided into four phases with a total of four steps:

1. Development of unknown document collections (Phase I: Identification)

2. Grouping of searching result amounts (Phase II. Classification); Subdivision of big inhomogeneous categories (allows better Classification)

3. Semi automatic creation of Main- and Sub-Clusters (Phase III: Virtualisation); Set up a basic organizational structure by process owner (Cluster Management, supervisor competence fields and competence team members).

4. Define cluster product creation and corpus of legislation (between companies) by cluster management (Phase IV: working base)

\section{CASE STUDY: DEFINING A CLUSTER DEVELOPMENT MODEL FOR THE MOBILE TELECOMMUNICATION}

The mobile communication cluster should become an innovative instrument of economic development.

Traditional economic development often does not achieve their goals. In particular, its primary goal: the creation of jobs, is usually far below expectations.

Fundamentals of European structural policy and the promotion of rural areas under Objective 2 are the following in Germany: The European Union follows with its structural policy, the objective of promoting economic and social cohesion among its Member States and to strengthen their regions. To this end it has a number of funding instruments and programs. As part of the so-called "Objective 2 funding," she supports others the economic and social development of rural areas in difficulty (formerly $5 b$ promotion). (Roth-Harting, Dr. B. 2007)

Excurse: Objectives and guidelines of the regional economic and structural policy (Objective 2/5b promotion) - Example of Rhineland-Palatinate in Germany:

Socio-economic conditions beyond the Objective 2 program is embedded in the general economic policies of the state of Rhineland-Palatinate. The primary objectives of this policy are the creation and preservation of jobs, the support - especially small and medium enterprises (SMEs), as well as the systematic enhance the environment and the promotion of start-up. In addition to creating growth and employment environment, targeted economic development is a major concern in economic policy, since in it a useful tool for increasing economic power, creating jobs and improving the competitiveness of the company.

Rhineland-Palatinate Infra-Structure Bank (ISB) founded in 1993 with the investment and structure of the German government (state basis). ISB should transport the country's pioneering approaches to economic development of Rhineland-Palatinate: The integration of all support measures ensures competent support for entrepreneurs as well as an extensive service and financing offerings. The support by the ISB is in the form of grants, low-interest loans, guarantees and equity investments. The economic development illustrates on individual areas of support and for various development schemes. This in particular various dimensions illustrates the embedding of EU aid policy in the economic policy of the state of RhinelandPalatinate.

Overview of Economic Development approved funds by funding areas in RhinelandPalatinate

Different grant programs were placed in the field of objective 2, such as farm-regional development and promotion of economic infrastructure. The regional conversion program embedded huge farm-technology promotion and especially the promotion of innovative 
technology-based start-ups in the field of research and technology infrastructure, technology consulting and technology transfer. The virtual R\&D Cluster focuses the regional promotion of the MCC strategy and MCC positioning. Enhanced energy promotion and promotion of vocational education boost other industries as well. Location marketing and support of trade fairs and international business contacts are important objective II fields. (Huebber, 2001)

Wide range area promotion which was distributed in structurally weak areas, grants and subsidies achieves a much lower success than those that promote the strengths of a specific region. These strengths can also be rewritten as a regional field of competence.

\section{Similar Historical Approaches}

A successful example of a natural cluster was the cluster in Solingen, Germany. For over 700 years, companies in the steel and steel processing industries located within a radius of Solingen and created a site expertise with a worldwide reputation.

Another successful example is the natural cluster (but without historical background such as steel production in Solingen). Silicon Valley is a "modern" cluster of information and communication technology with a worldwide reputation as well. And Silicon Valley is a natural cluster.

The development of non-historically evolved cluster, artificially generated and economic policy initiated by clusters require a dedicated cluster management. The successful cluster management means the management and control of a corporate network with the aim to promote this (brand to establish itself), but in particular increase the economic success of the company group (cluster). The cluster management consists of a strategic and operational management as well as an integrated technology infrastructure (web portal with knowledge base). All measures of cluster management are designed to the strengths of the company / region to strengthen and to create sustainable and positive developments on the regional labor market. Important cluster management tasks include an analysis of the economic performance of a region. For the success of a cluster companies with a sufficient power potential are necessary, such as its access to the market and their ability to innovate. A clear benefit expectancy and benefits orientation customs a basis for active participation for the cluster activities. The willingness for active exchange of knowledge sharing. Establishment and maintenance of mutual trust and supported by all network controller for coordination of cluster activities and for networking, both internally and externally (Scheer, et al, 2007).

Creation of a regional skills assessment (Regional Intellectual Capital - RIC). The RIC is the regional strengths and weaknesses profiles and shows which industries will build in future jobs or reduction in employment levels. As part of a regional skill assessments in systematic form the strengths are highlighted. The weighting of the regional weaknesses are an important prerequisite as well to plan the regional positioning of a cluster.

Definition of core competency areas of a region (corporate strengths). Regional core competencies include joined the corporate strength of all cluster companies. Core competencies in R \& D cluster MCC particular mobile application development, the logistics and inventory management, the supply of two-language human capital, the location close to the border are two European countries (Belgium and Holland) support the active involvement of local partners and conveyors. The involvement of regional partners is fundamental. It should be on a structured basis, since the competition situations occur often and partners have equal rights to participate. Recruitment of regionally and nationally leading companies / organizations for developing local businesses leadership position are very important for the overall project. There are companies used to have a regional level, which is sufficient to be able to implement a cluster strategy. The operationalization of a cluster management is determined by a number of factors. The most important and essential for the success of the cluster are those that are dependent on the organizational cooperation and gain immediate benefit-oriented tasks. Build a cluster organization (administration, management) as a form of 
organization to set up a cluster management and cluster administration. Establishment of a technical infrastructure (cluster site) by a cooperative association with low barriers to entry for customers, and Internet-based technologies in the process flow. Development of a cluster guideline (rules for a successful co-operation) need to be established for cooperation to achieve the smooth running with low potential for discussion as well. Competitors relations have to be given special consideration in that topic. Definition of a joint marketing strategy and organizational means for the overall organization start appropriate marketing activities and budget sourcing. A form of financing by promoting (for example using Objective 2) is usually necessary. Cluster development and strengthening is a strategic aspect that requires a well-functioning management. Definition of current services and controlling key figures are placed to assist in the operational implementation of the cluster strategy. Sustainable checking the figures using Appropriate IT infrastructure (data models) are treated in the technical implementation. It is also important, to define the "Cluster integrated" technology. The integrated technology in MCC includes 4 important groups (Roettmer, 2006).

1. Content Management Service (CMS) includes research and storage for company's and product information of active and upcoming cluster partners. It is the central base of an increasing VE. The CMS groupware solution is a web-based groupware system, which must be integrated into the existing infrastructure as possible without much additional effort.

2. Collaboration (COL) supports effective communication and cooperation tools as cloud services, central databases, file sharing and virtual work rooms. Besides the exchange of content, the type of exchange is important, because this may affect the business workflow positively and has to follow the same cluster principles.

3. Market Place (MP): Assumes to develop a cluster centralized market sharing. A commercialization of all cluster activities are intended as an incentive for cluster partners, who wish to apply to regional customers. Because cluster's activity immediately secondary commercial objectives, but of secondary importance, it makes sense to deal carefully with competitive situations.

4. Know how management (KHM) and knowledge balancing are the most important strategic tools on the long run. It supports the share of knowledge and the development of a cluster branding value.

Knowledge Management and Intellectual Capital is the most important strategic figure in Cluster development processes. Knowledge and new product development define the future business of a cluster. Capabilities and willingness of staff, efficient processes, availability of relevant information or a high proportion of repeat customers are factors of which the welfare of cluster depends. It has therefore the Federal Ministry of Economics and Labour mission is to promote knowledge management and intellectual capital and actively in the implementation especially in the SME sector (Wognum, 2002).

Knowledge management is concerned with the question of how can the corporate governance and development necessary knowledge systematically anchored in an organization. That includes more than employee's know how. Knowledge includes all the necessary data, information and skills required an operation to solve all the operational and strategic tasks, such as working processes and well being business initiated by cluster activities. Knowledge is now represented as another factor of production to make advanced economies such as in clusters remaining competitive.

The focal point for the collection, structuring and representation of knowledge a cluster has recently developed the intellectual capital. The term is for practitioners in parts of the invoice or taxation initially misleading. For an intellectual capital statement is (still) no balance in the true sense in which knowledge is represented by fixed rules, such as the assets 
in a trade or tax accounting. Rather, the intellectual capital is a tool which compresses the intellectual capital, human resources, business relationships and processes, and clear centrally at one point and federated results. Preparation and detection carried out in the three cluster dimensions (Edvinssan, 2001)

1. human capital, for example employee skills, employee behavior, training goodness

2. capital structure, e.g. internal processes, intellectual property (patents, rights, and organizational culture

3. relational capital, e.g. Customer and supplier relations, public relations, marketing

It is always the human capital, the employees of a company, the well prepared and motivated people working for cluster activities making cluster support regional successful.

\section{Benefits of Knowledge Management and Intellectual Capital for clusters rating}

But why should a company ever make the effort to grapple with the issue of knowledge management and intellectual capital? Finally, analysis of the operation and creation of intellectual capital are additional costs and extra work connected. The question is easy to answer, because medium and long term result from the separate representation of the intellectual capital very tangible benefits, such as

- Better representation of the "true" value of the company because not only monetary aspects to be considered (especially important in cluster with service-performance and high-tech industry)

- Compared with key business partners, such as suppliers or customers may, the advantages of their own enterprise comprehensively illustrated and demonstrated the who-(improvement of basic argumentation for cluster strategy)

- Internal be systematically detected strengths and weaknesses and it can be implemented in a targeted improvement measures

- Improvements in a cluster rating and thus easier access to fresh capital improvements

- Organization tool for recruitment of specialists and managers who can easily make a complete picture of company

Knowledge management is the most important prerequisite for the creation of an intellectual capital is the presence of a vision and a coherent, resulting accounting, corporate cluster strategy. This should include risks and opportunities arising from the current business environment, be included in the analysis of competition and technological operations. Formulation of goals and knowledge factors lead from vision and strategy embrace the goals for each dimension derived. These complement and complete the 'normal' business goals. Knowledge goals improving leadership skills, improving the skills and motivation of all employees, improving development and communication processes or expand business with customers and suppliers. (Mertins, 2005)

These are the objectives, the aim is to find each dimension three to five factors, which can be used to measure whether and to what extent resulting improvements in the objectives. In the area of human capital, factors enable employee skills, employee motivation and productivity. For the relational customer focus, strong supplier relationships or confidence needed. Human equity can for example describe with sustainable management, information and communication or-functioning processes. It is important that clear between objectives and factors are discernible relationships. An example of the human capital dimension to illustrate is if a goal is to improve employee motivation, etc. come as factors employee satisfaction, attendance rates and productivity. The change of these factors can be drawn valuable conclusions. This may be an indicator if satisfaction declines. (Probst, et al, 2003)

Self-evaluation of the initial state that ensures the factors are clear and easy to understand to make a proper evaluation and maintenance. It recommends the creation of a selfassessment and evaluation and will examine each factor based on the measured variables 
quality, quantity and systematic, to extent it and to achieving the goal of a particular dimension.

Knowledge balancing is a fairly new tool that makes it possible to grasp the increasing importance of intellectual capital of a company, analyze and present. The Intellectual Capital also represents issues that are present in similar in operation already, some figures for staff development, training and metrics for customer development. The derivation of knowledge goals and knowledge factors of the corporate vision and strategies are the basic of knowledge balancing. Knowledge balancing also serves as a communication and information tool to a third party, such as banking, suppliers or key customers is necessary for financing and valuing a cluster. Those obtained with the knowledge balance a good overview of the quality of the intellectual capital of the company and are able to carry out a proper evaluation, e.g. when a rating or the conclusion of contracts. At the same time the traditional financial statements is useful to complement the analysis of the soft factors and thus giving a basic stand.

Even if the intellectual capital is in literature and practice still under debate, it appears to be developing from today's perspective, an essential tool that helps to grasp the intellectual assets of a company systematically and let represent. Due to the ongoing legal activities at the national and international level is to be expected that the intellectual capital is established in the next few years in the business world.

Figure 2 illustrates the four main working groups: the interactions of the four main working groups cluster integrated technology.

Figure 2: Four main working groups and their interactions

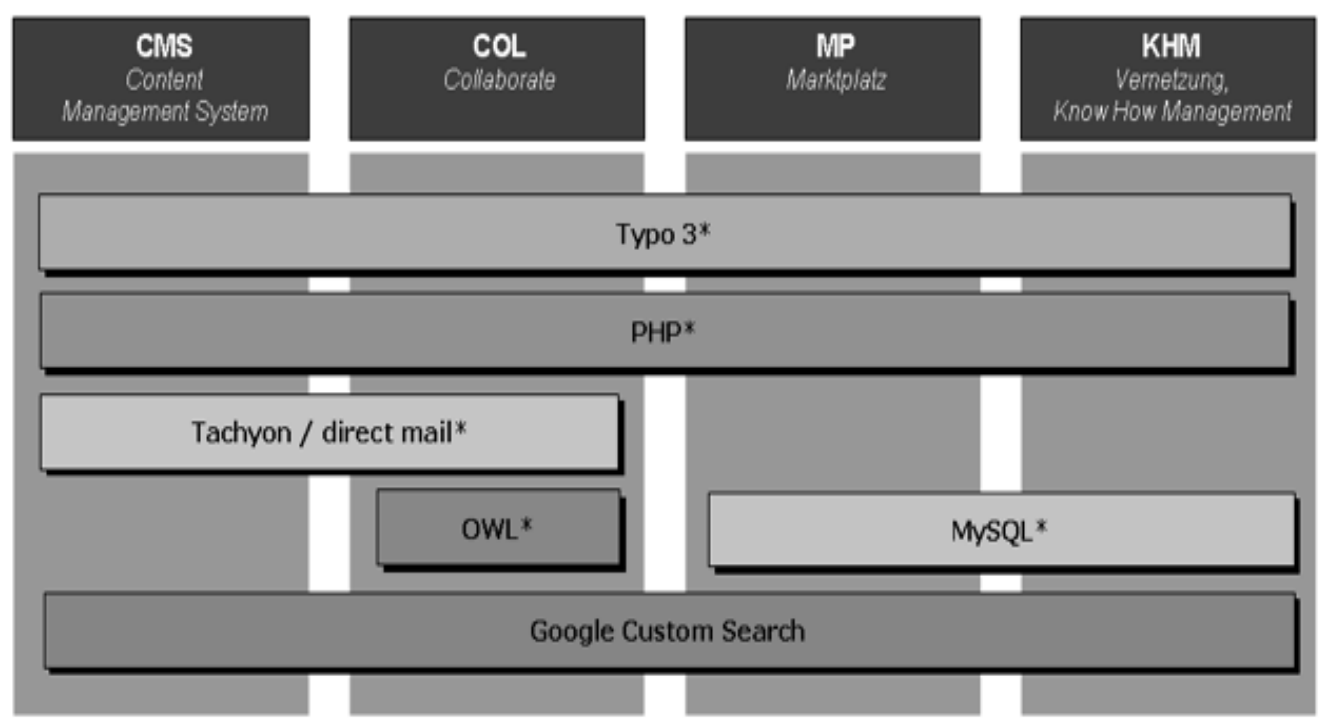

Source: Deutsche Telekom, department of new business development: working paper, regional cluster operations, p. 22, Bonn, 2007

Technical services MCC:

The technical description of the case study MCC mobile communication cluster shows the six internet based software types which support the strategy of MCC (knowledge managing, mobile communication, collaboration):

- Typo 3 is a web based content management system on an open source licence model. "Open source is a kind of software. It is different from other software because the source code is available to everyone. The source code is a set of instructions for the computer, written in a programming language. Anyone can see how the source code works and can change it if they want to make it work differently. The opposite of open source is closed source. Closed source software is not available to everyone. Open 
source is almost the same thing as free software. Open source and free software have been around for decades.

- PHP (PHP: Hypertext Preprocessor) is a scripting language that helps make webpages more interactive. It is an useful technique to simplify web programming.

- Direct mail is a licence based mailing software that allows to communicate is a professional way to a wide range of cluster members

- OWL is a licence based tool which enables cluster members to enhance their business in the cluster infrastructure (such as a web shop).

- MySQL is a database system used by many websites on the Internet. It allows individualizing specific custom need to create a virtual working base for cluster members and participants.

- Google custom search is a customized search engine that allows to reduce the search field onto the cluster based content and helps to reduce the variability of typical search questions to the cluster focus.

\section{RESULTS OF THE RESEARCH AND FUTURE STEPS}

Currently eighty active companies cooperate in four clusters. The four clusters are defining cluster offering services like a virtual enterprise made up of the individual companies. The core success factor is based on the "living" community supported by various technical solutions and the working field of knowledge management and knowledge distribution. To create market oriented offering portfolio based on aggregated individual competences (from research experts to product and market specialists) is the main factor inside the four (sub-) clusters. The cluster's rule type should be easy to understand and practically to work with. Considering the massiv competition is the most sensitive point for the cluster management and for the eighty companies involved.

However, beyond all difficulties the (theoretical) advantages of cooperative virtual networking overcapitalizes the business competition. The results of the analysis are collected in Table 1.

Table 1: Current results and project status

\begin{tabular}{|l|l|}
\hline \multicolumn{1}{|c|}{ Category } & \multicolumn{1}{c|}{ Description } \\
\hline \hline $\begin{array}{l}\text { product } \\
\text { development }\end{array}$ & $\begin{array}{l}\text { with the aid of different competences and partners (research, production, } \\
\text { sales, etc.) different branches and lines a fully market oriented offering } \\
\text { portfolio comes out }\end{array}$ \\
\hline cooperation success & $\begin{array}{l}\text { aggregated supplies provokes stronger market approach and encourages all } \\
\text { members of the virtual cluster }\end{array}$ \\
\hline technical platform & $\begin{array}{l}\text { open source framework (content management system) fitted with innovative } \\
\text { knowledge based solution (Nextbot) and added by different database } \\
\text { solutions (DBS) such as (company-, collaboration-, community (blogging), } \\
\text { information management- and dashboard-DBS) }\end{array}$ \\
\hline $\begin{array}{l}\text { regional knowledge } \\
\text { identification }\end{array}$ & $\begin{array}{l}\text { robots search and browse regional companies' web pages and create regional } \\
\text { knowledge profile }\end{array}$ \\
\hline cluster set up & $\begin{array}{l}\text { operational and organizational structure with defined responsibilities such as } \\
\text { cluster manager, industry line manager, cooperative manager, quality } \\
\text { assurance (will be installed soon) }\end{array}$ \\
\hline competence fields & $\begin{array}{l}\text { sector based professional groups with mobile focus such as m-industry, m- } \\
\text { business, m-health, m-security (more groups will be defined) }\end{array}$ \\
\hline $\begin{array}{l}\text { proposed technical } \\
\text { solution }\end{array}$ & $\begin{array}{l}\text { national provider such as Deutsche Telekom AG proposed solution for } \\
\text { regional business development organizations }\end{array}$ \\
\hline
\end{tabular}

Source: Deutsche Telekom, department of new business development: working paper, regional cluster operations, p. 28-33, Bonn, 2007 
The category column gives the key factors for the project and the description column reports the corresponding outcome of the still running project.

Since the creation of virtual enterprises is not restricted to external companies, the same process and technology might be applied in big trusts in order to discover new business opportunities by combining available internal competence (or to avoid double work!).

An internal analysis seems to be even more successful because there are no restrictions to the documents and further context information, e.g. human resource files, could be used, as well as internal product descriptions. Even though in that case the information base is much richer than in the general extra-enterprise case, the Seed Identification Problem remains. A typical scenario is that units in a company offer services to customers, but not inside the enterprise. Often a unit does not know the portefolio of its sister unit. Using automatic screens of the unit's documents in the way discussed above gives rise to potential service chains which - in bundle - offers the customer a solution in one hand. Another scenario is the combination of complex products. The chemical industry deals with secondary substances which are generated during the production of a prime product. Finding chemical processes which use the secondary substances to destillate a new primary product is one of the innovation processes in this industry. Analysing the respective production sheets together with scientific literature would open new product opportunities. More examples for product innovation in VEs may be found in (Popplewell and Harding, 2005) and (Wognum and Faber, 2002).

Acknowledgement: We would like to thank Prof. Dr. Heinz-Juergen Mueller - University of Cooperative Education, Mannheim, Germany, for his valuable insights

\section{REFERENCES}

1. Bartel., M. (2010): Open Innovation. Der offene Umgang mit Wissen verändert das Innovationsmanagement, published in Open Journal of Knowledge Management, Ausgabe I/2010, pp. 12-20, Berlin

2. Chesbrough, H. (2003): The Era of Open Innovation, MIT Sloan Management Review, Spring, pp2-14

3. Delgado, M, Porter, M. E., Stern, S. (2011): "Clusters, Convergence, and Economic Performance", Paper at the Scientific Conference of the Institute for Strategy and Competitiveness, pp. 22-65, Cambridge, March 11

4. Deutsche Telekom AG (2007): Department of new business development working papers, IuK Business Development - case study, pp. 12-18, Bonn, 2007 and working paper regional cluster operations, pp. 5-33, Bonn

5. Edvinssan, L, Bruning, G., (2000) asset knowledge capital, Gabler Verlag Wiesbaden

6. Eichler, G. (2011): Self organization in Enterprise 2.0 communities: to introduce a new experts' exchange application, Deutsche Telekom AG, Laboratories, Information Relevance, Bonn

7. Fitza, M. (2006): The Nextbot Knowledge Framework, Brainbot Whitepaper, Bonn, download from: http://pediapress.com/data/Nextbot_knowledge_framework_english.pdf

8. Journal of Intellectual Capital, http://www.emeraldinsight.com/Insight, request: 22.08.2011

9. Kanet, J.J. - Faisst, W. - Mertens, P. (1999): “Application of Information Technology to a Virtual Enterprise Broker: The case of Bill Epstein". In: International Journal of Production Economics, 62, pp. 23-32, vol. 62, issue 1-2

10. Magazine for knowledge management: http://www.wissensmanagement.net, request: 22.08.2011 
11. Mertins, K., Alwert, K., Heisig, P. (Eds.), (2005) Intellectual capital, Springer Verlag. Heidelberg

12. Huebber, G., in Ministry of Economics, Transport (2001), Agriculture and Viticulture: Rhineland-Palatinate. Balance of the Economic Development, pp. 7, Mainz

13. Nishimura, J., et al (2009): R\&D productivity and the organization of cluster policy: An empirical evaluation of the Industrial Cluster Project in Japan, pp. 10-23, Tokyo

14. Popplewell, K.; et al (2005): "Impact of Moderation through the Distributed Virtual Enterprise Life Cycle" in: Konstantas, D.; Bourrières, J.-P.; Léonard, M.; Boudjlida, N. (Eds.): Interoperability of Enterprise Software and Applications, Springer, Coventry

15. Porter, M. E. (1998): Clusters and the New Economics of Competition. Harvard Business Review, 76 (6), pp. 77-90, Cambridge

16. Probst, J., Raub, S., Romhardt, K., (2003) Managing knowledge - how companies use their valuable resource optimally, Gabler Verlag, Wiesbaden

17. Roettmer, N. - Katzy B. (2006): "Cluster Innovation Capabilities - A Contribution to Understanding Cluster Innovativeness". Center for Technology and Innovation Management, 1 Working Paper Series Working Paper No. 3706, Toronto

18. Rothgang, M. (2012): http://ejournals.duncker-humblot.de/doi/abs/10.3790/vjh

19. Rothgang, M., Lageman, B. (2011): "Innovationspolitischer Mehrwert durch Vernetzung?“: in: Cluster- und Netzwerkförderung als Politikinstrument auf Bundesund Länderebene", German Institute for Economic Research, pp. 124-148, Essen

20. Roth-Harting, B. (2007): Ministerium für Wirtschaft, Energie, Bauen, Wohnen und Verkehr des Landes Nordrhein-Westfalen Ref. IV.1, in NRW Ziel 2-Programm 2007 2013 (EFRE), pp. 1-3, Bonn

21. Scheer, G; Zallinger, L. (2007) Deutsche Gesellschaft für Technische Zusammenarbeit in Cluster Management and Cluster Processing, pp. 13-18, Berlin

22. Wognum, P.M. - Faber, E.C.C. (2002): "Infrastructures for collaboration in virtual organisations". In: International Journal of Networking and Virtual Organisations, Vol. 1, No. 1, pp. 32-54, Nijmegen

23. Working Group Intellectual Capital: www.akwissensbilanz.org request: 22.08.2011 